\title{
Analysis of Treatment Option for Synchronous Liver Metastases and Colon Rectal Cancer
}

\author{
Danilo Coco ${ }^{1^{*}}$, Silvana Leanza ${ }^{2}$ \\ ${ }^{1}$ Ospedali Riuniti Marche Nord, Pesaro, Italy; ${ }^{2}$ Carlo Urbani Hospital, Jesi, Ancona, Italy
}

\author{
Citation: Coco D, Leanza S. Analysis of Treatment \\ Option for Synchronous Liver Metastases and Colon \\ 15;
7(23):4176-4178 \\ https://doi.org/10.3889/oamjms.2019.796 \\ Keywords: Synchronous liver metastases; Colon recta \\ cancer; Treatment \\ *Correspondence: Danilo Coco. Ospedali Riuniti Marche \\ Nord, Pesaro, Italy. E-mail: webcostruction@msn.com \\ Received: 19-May-2019; Revised: 08-Jun-2019; \\ Accepted: 09-Jun-2019; Online first: 13-Dec-2019 \\ Copyright: $\odot 2019$ Danilo Coco, Silvana Leanza. This is \\ an open-access article distributed under the terms of the \\ Crealive Colichons A \\ Funding: This research did not receive any financial \\ support \\ Competing Interests: The authors have declared that no \\ competing interests exis
}

\begin{abstract}
Colorectal or bowel cancer is one of the major causes of cancer worldwide. Research has shown that 15 to $20 \%$ colorectal cancer patients are also diagnosed with synchronous liver metastases (LM) at presentation and about one third eventually develop liver lesions. Management of cases with colorectal cancer comorbid with liver metastases is more complex. This highlights the need for suggesting the need for effective treatment while optimizing timing during surgical and medical treatment of primary plus metastatic disease. Such patients cases are likely to present with severe cancer biology and thereby less likely to be long-term survivors.
\end{abstract}

\section{Introduction}

Colorectal or bowel cancer is one of the major cause of cancer worldwide. Research has shown that 15 to $20 \%$ colorectal cancer patients are also diagnosed with synchronous liver metastases (LM) at presentation and about one third eventually develop liver lesions [1], [2]. Management of cases with colorectal cancer comorbid with liver metastases is more complex [3], [4]. This highlights the need for suggesting the need for effective treatment while optimizing timing during surgical and medical treatment of primary plus metastatic disease. According to Fong, Fortner, Sun, Brennan, and Blumgart, 1999 [5], such patients cases are likely to present with severe cancer biology and thereby less likely to be long-term survivors.

The question as whether primary lesion surgery should precede metastases resection is still debatable. Logically, the management of these patients can be categorized into two groups. The first case is where the patients have hepatic disease synchronized with extrahepatic metastatic condition. These patients are treated with systemic chemotherapy as provided in the current treatment guidelines for patients with advanced multisite metastatic colorectal cancer disease [3], [6]. The second case is where patients have liver-limited synchronous metastatic disease which occurs frequently but yet a rising complex clinical management issue [7].

Conventionally, treatment of colorectal synchronous liver metastasis patients comprised colorectal primary tumour resection and then adjuvant chemotherapy in combination with liver resection [7], [8], [9]. However, Mentha, Majno, Andres, RubbiaBrandt, Morel, and Roth, 2006 [10], challenged this view by advocating for advanced synchronous liver metastases resection before the primary.

For patients with synchronous metastases, major advancements in liver surgery have led to two 
alternative options. The first involves synchronous liver metastases and colorectal primary resection synchronously [7], [9] which aims to remove macroscopic tumour burden through a single operation. However, this approach may lead to considerable complex morbidity with side effects on progression-free survival [11]. The second option starts with liver metastatic disease resection (i.e. reverse or liver-first approach) [10], [12]. This approach is commonly indicated for colorectal synchronous liver metastasis patients where rectal primary preoperative long-course chemoradiotherapy before surgical resection is likely to create a 'window' for liver resection [13], [14]. From oncological perspective, it is also arguable that the liver-first strategy is advantageous since it addresses the hepatic metastatic issue before it progresses into the liver which makes it unresectable [15]. The focus of this study is to determine the order to be followed while treating patients with synchronous liver metastases and colon rectal cancer (liver first, colon first or syncrhonus surgery).

\section{Methods}

This study used a systematic review method to collect data from previous peer review papers. The researcher conducted a search of the relevant articles from various databases, namely PubMed and SCOPUS sciencedirect as well as EMBASE plus NHS Knowledge Network. All the collected articles were then subjected to assessment criteria for relevance and only seven articles met this criteria for literature review.

\section{Results and Discussion}

A systematic review by Guraya, 2013 [16] found that a number of factors limit most patients from undergoing resection at initial stages. These are size, anatomic location, and extent of disease to insufficient remnant liver volume as well as comorbidities. However, surgery currently provides the best chance for curing colorectal liver metastases patients. The implication is that other treatment modalities must be explored to control or downsize hepatic lesions prior to surgical treatment. Currently, most patients are treated with systemic plus regional chemotherapy to complement the surgical intervention.

An expert opinion by Adam, 2007 [17], suggested that synchronous liver metastases management is changing with time. In his view, treatment of resectable lesions is open for either approach unlike irresectable lesions in which treatment starts with systemic chemotherapy. However, there is no evidence to support this approach as the first choice of treatment. The implication is that future research should explore on this issue using controlled trials.

In a study by Per Pfeiffer, Thomas and Robert, 2018 [18] it was reported that there is no clear optimal sequence and individual usage despite that its use on individual basis. Additionally, the authors recommended multidisciplinary approach along with decision making for patients with rectal cancer (RC) and synchronous metastases. In the case of a multidisciplinary approach, treatment aim is first defined followed by regular follow up, re-evaluation and re-discussion after every 2 months. The authors recommended treatment initiation starting with the most effective systemic chemotherapy (i.e. triplet chemotherapy along with targeted therapy in view of RAS status) in combination multidisciplinary team (MDT) re-evaluation every 2 months. Moreover, they recommended that liver surgery should be initiated once colorectal liver metastases (CRLM) becomes resectable followed by systemic treatment prior to and/or after primary resection for a minimum of 6 months. Furthermore, SC-RT may be combined with systemic chemotherapy at any point with or without minimal delay.

René, Aimery, Joan, Norihiro, Francis, Evelyne et al., 2015 [19] recommended treatment of synchronous CRLM starting with abdominal high-dose contrast-enhanced computed tomography (CT) to establish the possibility of resection. In their views, asymptomatic $\mathrm{CRC}$ along with resectable synchronous CRCLM should be treated with chemotherapy with radiotherapy or chemotherapy alone then either one-stage surgery if hepatic disease is limited and easy-to-resect primary tumours or by use staged surgery for other patients. In patients with asymptomatic CRC along with non-resectable synchronous CRCLM, optimal chemotherapy is performed to make LM resectable and then hepatic surgery and primary tumour resection. The third option is applicable to patients with symptomatic CRC along with resectable synchronous CRCLM. In this case, primary tumour resection of perforated or occlusive tumours is done unlike the bleeding tumours which may cause anaemia and then chemotherapy in combination with LM surgery. Where patients have symptomatic CRC with non-resectable synchronous CRCLM, primary tumour resection for perforated or occlusive tumours should first be performed, then chemotherapy and finally LM surgery in case tumour shrinkage occurs. Patients with tumours with bleeding that cause anaemia should be treated with induction chemotherapy to downsize both primary tumour plus LM before operating sites with more significant tumour load such as the liver.

Christian, Valentinus, Erik, Sam, Jan, Ingvar, \& Gert, 2017 [20], presented 109 patients with un- 
resected colorectal cancer 9CRC) along with synchronous liver metastases to a MDT conference. Seventy-five patients were indicated for liver-first and the remaining 34 for classical strategy. The findings showed that $35 \%$ patients failed to complete the liverfirst treatment versus 10 patients from the classical strategy $(P=0.664)$. The failure rate was attributable to the most frequently disease progression. There were 91 patients who received the primary tumor resection prior to the liver metastasesOf these, 67 were non-referrals and 24 after MDT allocation. Median survival following diagnosis in the primary tumour resection was 60 (48 to 73) months versus 46 (31 to 60$)$ months in the liver-first treatment group $(n=$ $49), \quad(P=0.310)$. The study concluded that a maximum of $35 \%$ colorectal cancer with synchronous liver metastases patients fail to complete the necessary liver plus bowel resections, regardless of the treatment strategy.

\section{Conclusion and Recommendations}

In general, this review found that the treatment order for patients with colorectal synchronous liver metastasis patients. The general observation is that patients with colorectal liver metastases should be treated with the most effective systemic chemotherapy in combination multidisciplinary team (MDT) re-evaluation every 2 months. However, liver surgery should be performed once colorectal liver metastases (CRLM) becomes resectable followed by systemic treatment prior to and/or after primary resection for at least 6 months. However, this study recommends the need for future research to ascertain the best treatment options based on patient needs.

\section{References}

1. Leporrier J, Maurel J, Chiche L, Bara S, Segol P, Launoy G. A population-based study of the incidence, management and prognosis of hepatic metastases from colorectal Cancer. Br J Surg. 2006; 93:46574. https://doi.org/10.1002/bjs.5278 PMid:16523446

2. Manfredi S, Lepage C, Hatem C, Coatmeur O, Faivre J, Bouvier AM. Epidemiology and management of liver metastases from colorectal Cancer. Ann Surg. 2006; 244:254-9.

https://doi.org/10.1097/01.sla.0000217629.94941.cf PMid:16858188 PMCid:PMC1602156

3. Schmoll HJ, Van Cutsem E, Stein A, Valentini V, Glimelius B, Haustermans $\mathrm{K}$, et al. ESMO Consensus guidelines for management of patients with colon and rectal cancer. a personalized approach to clinical decision making. Ann Oncol. 2012; 23:2479-516. https://doi.org/10.1093/annonc/mds236 PMid:23012255

4. Bismuth $\mathrm{H}$, Castaing $\mathrm{D}$, Traynor $\mathrm{O}$. Surgery for synchronous hepatic metastases of colorectal Cancer. Scand J Gastroenterol Suppl. 1988; 149:144-9. https://doi.org/10.3109/00365528809096972 PMid:3201153
5. Fong Y, Fortner J, Sun RL, Brennan MF, Blumgart LH. Clinical score for predicting recurrence after hepatic resection for metastatic colorectal Cancer: analysis of 1001 consecutive cases. Ann Surg. 1999; 230:30918. https://doi.org/10.1097/00000658-199909000-00004 PMid:10493478 PMCid:PMC1420876

6. National Institute of Clinical Excellence. Colorectal Cancer: the diagnosis and management of colorectal Cancer. Clinical Guideline CG, 2011:131.

7. Brouquet A, Mortenson MM, Vauthey JN, Rodriguez-Bigas MA, Overman MJ, Chang GJ, et al. Surgical strategies for synchronous colorectal liver metastases in 156 consecutive patients: classic combined or reverse strategy? J Am Coll Surg. 2010; 210(6):934-41. https://doi.org/10.1016/j.jamcollsurg.2010.02.039 PMid:20510802

8. Adam R, Lucidi V, Bismuth $\mathrm{H}$. Hepatic colorectal metastases: methods of improving resectability. Surg Clin North Am. 2004; 84:65971. https://doi.org/10.1016/i.suc.2003.12.005 PMid:15062667

9. de Haas RJ, Adam R, Wicherts DA, Azoulay D, Bismuth H, Vibert E, Salloum C, Perdigao F, Benkabbou A, Castaing D. Comparison of simultaneous or delayed liver surgery for limited synchronous colorectal metastases. Br J Surg. 2010; 97:1279-89.

https://doi.org/10.1002/bis.7106 PMid:20578183

10. Mentha G, Majno PE, Andres A, Rubbia-Brandt L, Morel P, Roth AD. Neoadjuvant chemotherapy and resection of advanced synchronous liver metastases before treatment of the colorectal primary. Br J Surg. 2006; 93:872-8. https://doi.org/10.1002/bis.5346 PMid:16671066

11. Hillings $\varnothing \mathrm{JG}$, Wille-Jørgensen $P$. Staged or simultaneous resection of synchronous liver metastases from colorectal Cancer--a systematic review. Colorectal Dis. 2009; 11(1):3-10. https://doi.org/10.1111/j.14631318.2008.01625.x PMid:18637099

12. Siriwardena AK, Mason JM, Mullamitha S, Hancock HC, Jegatheeswaran S. Management of colorectal Cancer presenting with synchronous liver metastases. Nat Rev Clin Oncol. 2004; 11(8):446-59. https://doi.org/10.1038/nrclinonc.2014.90 PMid:24889770

13. Aklilu M, Eng C. The current landscape of locally advanced recta Cancer. Nat Rev Clin Oncol. 2011; 8(11):649-59. https://doi.org/10.1038/nrclinonc.2011.118 PMid:21826084

14. Sagar J. Colorectal stents for the management of malignant colonic obstructions. Cochrane Database of Systematic Reviews. 2011(11). https://doi.org/10.1002/14651858.CD007378.pub2 PMid:22071835 PMCid:PMC6885054

15. de Jong MC, van Dam RM, Maas M, Bemelmans MH, Damink SW Beets GL, Dejong $\mathrm{CH}$. The liver-first approach for synchronous colorectal liver metastasis: a 5-year single-centre experience. HPB. 2011; 13(10):745-52. https://doi.org/10.1111/j.1477-2574.2011.00372.x PMid:21929676 PMCid:PMC3210977

16. Guraya SY. Modern oncosurgical treatment strategies for synchronous liver metastases from colorectal cancer. Journal of Microscopy and Ultrastructure. 2013 Jun 1;1(1-2):1-7 https://doi.org/10.1016/i.jmau.2013.06.004

17. Adam R. Colorectal cancer with synchronous liver metastases. British Journal of Surgery: Incorporating European Journal of Surgery and Swiss Surgery. 2007; 94(2):129-31. https://doi.org/10.1002/bjs.5764 PMid:17256808

18. Pfeiffer P, Gruenberger T, Glynne-Jones R. Synchronous liver metastases in patients with rectal cancer: can we establish which treatment first? Ther Adv Med Oncol. 2018; 10:1 -10. https://doi.org/10.1177/1758835918787993 PMid:30093921 PMCid:PMC6081759

19. Adam R, de Gramont A, Figueras J, Kokudo N, Kunstlinger F, Loyer E, Poston G, Rougier P, Rubbia-Brandt L, Sobrero A, Teh C. Managing synchronous liver metastases from colorectal cancer: a multidisciplinary international consensus. Cancer treatment reviews. 2015; 41(9):729-41. https://doi.org/10.1016/i.ctrv.2015.06.006 PMid:26417845

20. Sturesson C, Valdimarsson VT, Blomstrand E, Eriksson S, Nilsson JH, Syk I, Lindell G. Liver-first strategy for synchronous colorectal liver metastases-an intention-to-treat analysis. Hpb. 2017; 19(1):52-8. https://doi.org/10.1016/i.hpb.2016.10.005 PMid:27838252 